MSC 60H30, 60H10

DOI: $10.14529 / \mathrm{mmp} 190313$

\title{
ANISOTROPIC DIFFUSION IN ANISOTROPIC STEPANOV SPACES
}

\author{
V.A. Gorlov, N.E. Zhukovsky and Y.A. Gagarin Air Force Academy, Voronezh, \\ Russian Federation, gorlov.v.a@gmail.com
}

We consider a problem on the image processing and computer vision. A wide range of methods allows to solve problems of this type. The methods of partial differential equations are the most useful and interesting ones. A non-linear diffusion takes special place in these studies. In this context, fundamental theoretical foundation is a central part of this approach. Therefore, we introduce a new functional class of spaces, formulate and prove the lemma on the equivalent norms in anisotropic Stepanov spaces. Another important result of this study is the lemma that the anisotropic Stepanov spaces are Banach. In addition, we obtain the theorem on the solvability of the equation of anisotropic diffusion in anisotropic Stepanov spaces. The results can be applied to the image processing and computer vision. Also, the obtained results open the new view to this problem.

Keywords: diffusion; Nikol'skii spaces; anisotropic Stepanov spaces; anisotropic diffusion; differential equations.

Dedicated to Yu. Gliklikh's 70-th birthday.

\section{Introduction}

As is known, partial differential equations (PDEs) have led to an entire new field in image processing and computer vision $[1,2]$. The PDE-based methods play a central role in hundreds of papers published during the last decade, and are discussed in several conferences and workshops. The success of this method is not really surprising, since PDEs have proved their usefulness in several areas such as physics and engineering sciences during a very long time. A non-linear diffusion takes a special place in these studies. Note a method of this type proposed by Perona and Malik in 1987 [3]. In order to smooth an image and, simultaneously, to enhance important features such as edges, Perona and Malik apply a diffusion process, where diffusivity is controlled by derivatives of the formed image. These filters are difficult to analyse mathematically, because the filters should act locally like an inverse diffusion process. This gives rise to issues on well-posedness. On the other hand, non-linear diffusion is widespread method with very effective results. Therefore, this method needs for a theoretical foundation. We consider a new class of functions, which opens a new view to this issues. This class is formed by the anisotropic Stepanov spaces. The proofs of some statements for these classes are based on non-linear analysis of partial differential equations and functionals.

\section{Preliminaries on Mean Derivatives}

Let $\bar{p}=\left(p_{1}, \ldots, p_{n}\right)$ and $\bar{l}=\left(l_{1}, \ldots, l_{n}\right)$ be vectors with coordinates $1 \leq p_{i} \leq \infty$, $0<l_{i}<\infty$, where $i=1, \ldots, n$. Consider the parallelepiped $I_{\bar{l}}=I_{l_{1}} \times \cdots \times I_{l_{n}} \subset \mathbb{R}^{n}$ with 
the edges $I_{l_{i}}=\left\{x_{i}: 0<x_{i}<l_{i}\right\}$. Following Nikol'skii [4, p. $9 ; 5$, p. 30], by $L_{\bar{p}}\left(I_{\bar{l}}\right)$ we denote the space of measurable functions $f(x)=f\left(x_{1}, \ldots, x_{n}\right)$ on $I_{\bar{l}}$ such that the norm

$$
\|f\|_{\bar{p}, \bar{l}}=\left\{\int_{I_{l_{n}}}\left[\cdots\left\{\int_{I_{l_{2}}}\left(\int_{I_{l_{1}}}|f(x)|^{p_{1}} d x_{1}\right)^{\frac{p_{2}}{p_{1}}} d x_{2}\right\}^{\frac{p_{3}}{p_{2}}} \cdots\right]^{\frac{p_{n}}{p_{n}-1}} d x_{n}\right\}^{\frac{1}{p_{n}}}
$$

is finite. Note importance of the order in which the norms are taken with respect to different variables. If $p_{i}=p(i=1, \ldots, n)$, then $\|f\|_{\bar{p}, I_{\bar{l}}}=\|f\|_{p, I_{\bar{l}}}$.

The spaces $L_{\bar{p}}\left(I_{\bar{l}}\right)$ are called the $L_{\bar{p}}$ anisotropic Nikol'skii spaces. As is known, these spaces are Banach with norm (1). Nikol'skii began the study of these spaces in relation to the theorems on embeddings of spaces of functions having generally different behavior in different directions. If norm (1) is considered for functions defined on unbounded sets, in particular, on the entire space $\mathbb{R}^{n}$, then the corresponding anisotropic Nikol'skii spaces lose many important properties, such as embedding properties with respect to the parameter $\bar{p}$, existence of important classes of bounded functions, etc.

Therefore, there is an interest in extension of classes of such spaces under which these properties are preserved. From this point of view, the Stepanov spaces $S_{p}\left(\bar{R}^{n}\right)[6$, p. 110; 7, p. 40] of locally integrable functions with the norm

$$
\|f\|_{S_{p, l}}=\sup _{\bar{t} \in \mathbb{R}^{n}}\left[\int_{I_{l}} \mid f(\bar{x}+\bar{t})^{p} d x\right]^{\frac{1}{p}}=\sup _{\bar{t} \in \mathbb{R}^{n}}\|T(\bar{t}) f\|_{L_{p}, I_{l}}
$$

are the spaces closest to the anisotropic Nikol'skii spaces. In order to investigate various properties of such functions with respect to different variables by Nikol'skii approach, we introduce the anisotropic Stepanov spaces $S_{\bar{p}, \bar{l}}$ as the sets of locally integrable functions on $\mathbb{R}^{n}$ with the norm

$$
\|f\|_{S_{\bar{p}, \bar{l}}}=\sup _{\bar{t} \in \mathbb{R}^{n}}\|T(\bar{t}) f\|_{L_{\bar{p}}, I_{\bar{l}}}
$$

Obviously, these sets of functions form normed linear spaces. Moreover, in this article, we consider the question on the close relationship between such spaces and anisotropic Nikol'skii spaces, as well as the problem on solvability of anisotropic diffusion in these spaces.

\section{Main Result}

As is known [6, p. 99], various equivalent norms can be defined on the classical Stepanov spaces $S_{p}\left(\mathbb{R}^{n}\right)$. The same is true for the spaces $S_{\bar{p}, \bar{l}}$.

Lemma 1. Norms (3), corresponding to different $\bar{l}^{(1)}=\left(l_{1}^{(1)}, \ldots, l_{n}^{(1)}\right)$, are equivalent.

Proof. Suppose that $l=\left(l_{1}, \ldots, l_{n}\right), \quad l_{0}=\max _{1 \leq i \leq n} l_{i}$, and $\vec{l}^{0}=\left(l_{0}, \ldots, l_{0}\right)$. Let us show that the norms $\|f\|_{S_{\bar{p}, \bar{l}}}$ and $\|f\|_{S_{\bar{p}, \bar{l}_{0}}}$ are equivalent.

On the one hand, we have

$$
\|f\|_{S_{\bar{p}, \bar{l}}} \leq\|f\|_{S_{\bar{p}, \bar{l}_{0}}} .
$$


On the other hand, suppose that $l_{0}=m_{i} l_{i}+\Theta_{i}$, where $0 \leq \Theta_{i} \leq 1$ and $m_{i}$ are positive integers. Then we have

$$
\begin{aligned}
& \left\{\int_{0}^{l_{0}}\left[\cdots\left\{\int_{0}^{l_{0}}\left(\int_{0}^{l_{0}}|f(x+\bar{t})|^{p_{1}} d x_{1}\right)^{\frac{p_{2}}{p_{1}}} d x_{2}\right\}^{\frac{p_{3}}{p_{2}}} \cdots\right]^{\frac{p_{n}}{p_{n}-1}} d x_{n}\right\}^{\frac{1}{p_{n}}} \leq \\
& \leq\left\{\int_{0}^{\left(m_{n}+1\right) l_{n}}\left[\cdots\left\{\int_{0}^{\left(m_{2}+1\right) l_{2}}\left(\int_{0}^{\left(m_{1}+1\right) l_{1}}|f(x+\bar{t})|^{p_{1}} d x_{1}\right)^{\frac{p_{2}}{p_{1}}} d x_{2}\right\}^{\frac{p_{3}}{p_{2}}} \cdots\right]^{\frac{p_{n}}{p_{n}-1}} d x_{n}\right\}^{\frac{1}{p_{n}}}= \\
& =\left\{\sum _ { k _ { n } = 0 } ^ { m _ { n } } \int _ { k _ { n } l _ { n } } ^ { ( k _ { n } + 1 ) l _ { n } } \left[\cdots \left\{\sum_{k_{2}=0}^{m_{2}} \int_{k_{2} l_{2}}^{\left(k_{2}+1\right) l_{2}} \times\right.\right.\right. \\
& \left.\left.\left.\times\left(\sum_{k_{\digamma}=0}^{m_{1}} \int_{k_{1} l_{1}}^{\left(m_{1}+1\right) l_{1}}|f(x+\bar{t})|^{p_{1}} d x_{1}\right)^{\frac{p_{2}}{p_{1}}} d x_{2}\right\}^{\frac{p_{3}}{p_{2}}} \cdots\right]^{\frac{p_{n}}{p_{n-1}}} d x_{n}\right\}^{\frac{1}{p_{n}}}= \\
& \begin{array}{c}
=\left\{\int_{0}^{\left(m_{n}+1\right) l_{n}}\left[\cdots\left\{\int_{0}^{\left(m_{2}+1\right) l_{2}}\left(\int_{0}^{\left(m_{1}+1\right) l_{1}}|f(x+\bar{t})|^{p_{1}} d x_{1}\right)^{\frac{p_{2}}{p_{1}}} d x_{2}\right\}^{\frac{p_{3}}{p_{2}}} \cdots\right]^{\frac{p_{n}}{p_{n-1}}} d x_{n}\right\}^{\frac{1}{p_{n}}}= \\
=\left\{\sum_{k_{n}=0}^{m_{n}} \int_{0}^{l_{0}} \cdots\left\{\sum_{k_{\Sigma}=0}^{m_{2}} \int_{0}^{l_{2}}\left(\sum_{k_{F}=0}^{m_{1}} \int_{0}^{l_{1}}|f(x+\bar{t}+\overline{k l})|^{p_{1}} d x_{1}\right)^{\frac{p_{2}}{p_{1}}} d x_{2} \ldots\right]^{\frac{p_{n}}{p_{n}-1}} d x_{n}\right\}^{\frac{p_{n}}{p_{n}}},
\end{array}
\end{aligned}
$$

where $\overline{k l}=\sum_{i=1}^{n} k_{i} l_{i}$.

Apply the inequalities

$$
\begin{aligned}
& S_{n}^{(\alpha)} \leq S_{n}^{\alpha} \leq n^{\alpha-1} S_{n}^{(\alpha)}, \quad \text { if } \quad \alpha \geq 1 ; \\
& n^{\alpha-1} S_{n}^{(\alpha)} \leq S_{n}^{\alpha} \leq S_{n}^{(\alpha)} \quad \text { if } \quad 0 \leq \alpha \leq 1
\end{aligned}
$$

and obtain

$$
\begin{gathered}
\left\|T_{\bar{t}} f\right\|_{L_{\bar{p}, I_{l}}} \leq C(\bar{p}, \bar{m}) \times \\
\times \sum_{k_{n}=0}^{m_{n}} \ldots \sum_{k_{1}=0}^{m_{1}}\left\{\int_{0}^{l_{n}} \ldots \int_{0}^{l_{2}}\left(\int_{0}^{l_{1}}|f(x+\bar{t}+\overline{k l})|^{p_{1}} d x_{1}\right)^{\frac{p_{2}}{p_{1}}} \ldots d x_{n}\right\}^{\frac{1}{p_{n}}},
\end{gathered}
$$

where $\bar{m}=\left(m_{1}, \ldots, m_{n}\right)$. Take the supremum over $\bar{t} \in \mathbb{R}^{n}$ and obtain the inequality

$$
\|f\|_{S_{\bar{p}, \bar{l}_{0}}} \leq C(\bar{p}, \bar{m}) \cdot\|f\|_{S_{\bar{p}, \bar{l}}}
$$

The statement of the lemma follows from (4) and (7).

Based on the results of Lemma 1 , we assume that $\bar{l}=(1, \ldots, 1)$ and consider the norm $\|f\|_{S_{\bar{p}, \overline{1}}}$. Let $K$ be the unit cube $0<x_{i} \leq 1,(i=1, \ldots, n)$, and $K_{\bar{m}}$ be the cube $K$ shifted 
by the vector $\bar{m}$. Therefore, $K_{\bar{m}} \bigcap K_{\bar{r}}=\emptyset$, if $\bar{m} \neq \bar{r}$ and $\bigcup_{\bar{m}} K_{\bar{m}}=\mathbb{R}^{n}$. In the spaces $S_{\bar{p}, \overline{1}}$, we use the cover of $\mathbb{R}^{n}$ by the cubes $K_{\bar{m}}$ in order to define the equivalent norm on the spaces $S_{\bar{p}, \overline{1}}$ as follows:

$$
\|f\|_{S_{\bar{p}, 0}}=\sup _{\bar{m}}\|f\|_{L_{\bar{p}, K_{\bar{m}}}} .
$$

Indeed, on the one hand,

$$
\|f\|_{S_{\bar{p}, 0}} \leq\|f\|_{S_{\bar{p}, \overline{1}}} .
$$

In order to prove the reverse inequality, we use (6) and obtain

$$
\begin{gathered}
\left\|T_{\bar{t}} f\right\|_{L_{\bar{p}, k}} \leq C(\bar{p}, \bar{m}) \times \\
\times \sum_{k_{n}=0}^{m_{n}} \cdots \sum_{k_{1}=0}^{m_{1}}\left\{\int_{\left[t_{n}\right]}^{\left[t_{n}\right]+2} \cdots \int_{\left[t_{2}\right]}^{\left[t_{2}\right]+2}\left(\int_{\left[t_{1}\right]}^{\left[t_{1}\right]+1}|f(x+\overline{k l})|^{p_{1}} d x_{1}\right)^{\frac{p_{2}}{p_{1}}} \ldots d x_{n}\right\}^{\frac{1}{p_{n}}} .
\end{gathered}
$$

In (10), we represent the corresponding integrals as

$$
\int_{\left[t_{i}\right]}^{\left[t_{i}+2\right]}=\int_{\left[t_{i}\right]}^{\left[t_{i}+1\right]}+\int_{\left[t_{i}\right]+1}^{\left[t_{i}+2\right]}
$$

where $i=1, \ldots, n$, once more use (6), take the supremum over $\bar{t} \in \mathbb{R}^{n}$, and obtain

$$
\|f\|_{S_{\bar{p}, \bar{l}}} \leq C(\bar{p}, \bar{m}) \cdot\|f\|_{S_{\bar{p}, 0}}
$$

The statement follows from (9) and (11). Hence, since the spaces $L_{\bar{p}, k}$ are separable on each cube $K_{\bar{m}}$, then the spaces $S_{\bar{p}, 0}$ are separable and, therefore, the spaces $S_{\bar{p}, \bar{l}}$ are separable.

Lemma 2. The spaces $S_{\bar{p}, \bar{l}}$ are Banach.

Proof. The proof is based on the following fact about vector-valued function defined on some abstract set and taking values in the Banach space $E$. This fact was developed by Hille and Phillips [8, p. 103]. If $f(\sigma)$ is strongly measurable on $\mathfrak{G}$ and $\|f(\sigma)\|_{E}$ is bounded everywhere except for some set having zero measure, then the space $L_{\infty}(\sigma, E)$ is Banach with the norm $\|f\|_{\infty}=\|f(\sigma)\|_{E}$. If $\|f(\sigma)\|_{E}$ is continuous, then $\|f\|=\sup _{\sigma \in \mathfrak{G}}\|f(\sigma)\|$ and $L_{\infty}(\sigma, E)$ becomes $C(\sigma, E)$. The statement of Lemma 2 follows from this statement, if $E=L_{\bar{p}, \bar{l}}$ and $\mathfrak{G}=\mathbb{R}^{n}$, since the spaces $L_{\bar{p}, \bar{l}}$ are complete.

Let $K_{l}^{n} \subset \mathbb{R}^{n}$ be the cube with the edges $0 \leq x_{i} \leq l$, and $K_{\bar{t}, l}^{n}$ be the cube $K_{l}^{n}$ shifted by the vector $\bar{t}=\left(t_{1}, \ldots, t_{n}\right)$. Consider the biconvex functional

$$
B_{l}(f, g)=\sup _{\bar{t} \in \mathbb{R}^{n}}\left|\int_{K_{l}^{n}} f(\bar{x}+\bar{t}) g(\bar{x}+\bar{t}) d \bar{x}\right|=\sup _{\bar{t} \in \mathbb{R}_{l}^{n}}\left|\int_{K_{\bar{t}, l}^{n}} f(x) g(x) d x\right| .
$$

The functional $B_{l}(f, g)$ is finite, if $f \in S_{\bar{p}, l}, g \in S_{\bar{p}^{\prime}, l}$. The proof of this statement is based on the Holder inequality for the norms on $L_{p}(\Omega)$ and $L_{p^{\prime}}(\Omega)[1$, p. 19]:

$$
\left|\int_{K_{\bar{t}}^{n}} f(x) g(x) d x\right| \leq\|f\|_{L_{p}} \cdot\|g\|_{L_{p^{\prime}}\left(K_{\bar{t}}\right)} .
$$


Hence, take supremum over $\bar{t} \in \mathbb{R}^{n}$ and obtain

$$
\left|B_{l}(f, g)\right| \leq\|f\|_{S_{\bar{p}, l}} \cdot\|g\|_{S_{\bar{p}^{\prime}, l}} .
$$

It is easy to see that (14) implies also the inequality

$$
\left|B_{l}(f, g)\right| \leq\|f\|_{S_{\bar{p}, l}} \cdot\|g\|_{L_{\bar{p}^{\prime}}\left(\mathbb{R}^{n}\right)} .
$$

Therefore, the following theorem is valid.

Theorem 1. The following equalities are valid:

$$
\begin{aligned}
& \|f\|_{S_{\bar{p}, l}}=\sup _{\|g\|_{\bar{p}^{\prime}}=1}\left|B_{l}(f, g)\right|, \\
& \|g\|_{L_{\bar{p}}}=\sup _{\|f\|_{S_{\bar{p}^{\prime}, l}=1}\left|B_{l}(f, g)\right| .}
\end{aligned}
$$

Proof. Let us prove (16). If $1 \leq p \leq \infty$, the function $f(x)$ is measurable on $\bar{R}^{n}$ and satisfies

$$
\left|B_{l}(f, g)\right| \leq M\|g\|_{L_{\bar{p}^{\prime}}\left(\mathbb{R}^{n}\right)}
$$

for any function $g \in \dot{L}_{\infty}\left(\mathbb{R}^{n}\right)$, where $\dot{L}_{\infty}\left(\mathbb{R}^{n}\right)$ is a set of measurable essentially bounded and finite functions, then $f \in S_{\bar{p}, \bar{l}}$ and

$$
M=\|f\|_{S_{\bar{p}, \bar{l}}}
$$

Following the proof of the similar statement proposed by Nikol'skii [1, p. 19], we assume that $s$ is the number of infinite components of the vector $\bar{p}, 0 \leq s \leq n$, while the remaining components are finite.

Suppose that the statement is false and the inequality $\|f\|_{S_{\bar{p}, \bar{l}}}>M$ holds for some function $f(x)$. In this case, there exists $\bar{t}_{0} \in \mathbb{R}^{n}$ for which

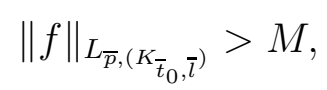

and we can find a positive integer $k$ such that the function

$$
\varphi(x)=\left\{\begin{array}{cl}
|f(x)|, & \text { if }|f(x)|<k \text { and } x \in K_{\bar{t}_{0}, \bar{l}} \\
k, & \text { if }|f(x)| \geq k \text { and } x \in K_{\bar{t}_{0}, \bar{l}} \\
0, & \text { if }
\end{array}\right.
$$

satisfies the inequality

$$
\|\varphi\|_{L_{\bar{p}}\left(K_{\bar{t}_{0}, l}\right)}>M
$$

Next, we use the Nikol'skii functions [1, p. 20], which are defined as follows. For $p_{i}<\infty$, we assume that

$$
\psi_{i}\left(x_{i} m, \ldots, x_{n}\right)=\left(\|\psi\|_{\left(p_{1}, \ldots, p_{i-1}\right), K_{\bar{t}_{0}, \bar{l}}^{i-1}} \cdot\|\varphi\|_{\left(p_{1}, \ldots, p_{i}\right), K_{\bar{t}_{0}, \bar{l}}^{i}}^{-1}\right)^{p_{i}-1}
$$


(for $i=1$ we suppose that $\|\varphi\|_{L_{\bar{p}_{i-1}}}=|\varphi|$ ), then $\psi_{i}=0$, if $\|\varphi\|_{L_{\bar{p}_{i}}}=0$. For $p=\infty$, we assume that

$$
\psi_{i}\left(x_{i} m, \ldots, x_{n}\right)=\left\{\begin{array}{cll}
\frac{\chi_{F_{i}}\left(x_{i}, \ldots, x_{n}\right)}{m_{i} F_{i}}, & \text { if } & m_{i} F_{i} \neq 0 \\
0, & \text { if } & m_{i} F_{i}=0
\end{array}\right.
$$

where $F_{i}=\left\{\left(x_{i}, \ldots, x_{n}\right):\|\varphi\|_{\left(p_{1}, \ldots, p_{i-1}\right), I_{1} \times \cdots \times I_{i-1}}>\|\varphi\|_{\left(p_{1}, \ldots, p_{i}\right), I_{1} \times \cdots \times I_{i}}\right\}, m_{i} F_{i}$ is the measure of the one-dimensional section of the set $F_{i}$ over $x_{i}$ for fixed $x_{i+1}, \ldots, x_{n}$, and $\chi_{F_{i}}$ is the characteristic function of the set $F_{i}$.

It is easy to see that $g \in \dot{L}_{\infty}\left(\mathbb{R}^{n}\right),\|g\|_{L_{\bar{p}^{\prime}}}=1$ and

$$
\int_{\mathbb{R}^{n}}|\varphi(x) g(x)| d x=\int_{K_{\bar{t}_{0}, \bar{l}}^{n}}|\varphi(x) g(x)| d x \geq\|\varphi\|_{L_{\bar{p}, l}\left(K_{\bar{t}_{0}, l}^{n}\right)}>M .
$$

Hence, we take into account (20) and obtain

$$
\begin{aligned}
\left|B_{l}(f, g)\right| & =\sup _{\bar{t} \in \mathbb{R}^{n}}\left|\int_{K^{n}} f(x) g(x) d x\right|=\int_{K_{\bar{t}_{0}, \bar{l}}^{n}}|f(x) g(x)| d x \geq \\
& \geq \int_{K_{\bar{t}_{0}, \bar{l}}^{n}}\left|\varphi(x)\|g(x) \mid d x \geq\| \varphi \|_{L_{\bar{p}, \bar{l}}}>M .\right.
\end{aligned}
$$

Therefore, we obtain the estimate

$$
\left|B_{l}(f, g)\right|>M\|g\|_{L_{\bar{p}^{\prime}}\left(\mathbb{R}^{n}\right)},
$$

which contradicts to (18). This completes the proof.

Therefore, on the one hand,

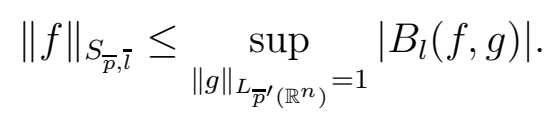

On the other hand,

$$
\sup _{\|g\|_{L_{\bar{p}^{\prime}\left(\mathbb{R}^{n}\right)}=1}}\left|B_{l}(f, g)\right| \leq\|f\|_{S_{\bar{p}, \bar{l}}} .
$$

The proof of equality (16) follows from inequalities (22) and (23). Equality (17) is proved in the same way.

Theorem 2. The partial differential equation

$$
\begin{gathered}
\frac{\partial u(t, x)}{\partial t}=\operatorname{div}(D \nabla u(t, x)), \\
u(x, 0)=\varphi(x)
\end{gathered}
$$

is solvable in the spaces $\bar{S}_{\bar{p}, \bar{l}}\left(R^{n}\right)$, and there exists the estimate

$$
\|u(t, x)\|_{\bar{S}_{\bar{p}, \bar{l}}\left(\mathbb{R}^{n}\right)} \leq\|\varphi\|_{\bar{S}_{\bar{p}, \bar{l}}\left(\mathbb{R}^{n}\right)} .
$$

Acknowledgements. The research is partially supported by RFBR Grant no. 18-0100048. 


\section{References}

1. Gliklikh Yu.E. Global and Stochastic Analysis with Applications to Mathematical Physics. London, Springer, 2011.

2. Deimling K. Multivalued Differential Equations. Berlin, New York, Walter de Gruyter, 1992.

3. Perona P., Malik J. Scale-Space and Edge Detection Using Anisotropic Diffusion. IEEE Transactions on Pattern Analysis and Machine Intelligence, 1990, vol. 12, no. 7, pp. 629-639.

4. Besov O.V., Il'in V.P., Nikol'skii S.M. Integral'nye predstavleniya funkciy i teoremy vlozheniya [Integral Representations of Functions and Embedding Theorems]. Moscow, Nauka, 1975. (in Russian)

5. Nikol'skii S.M. Priblizhenie funkciy mnogih peremennyh i teoremy vlozheniya [Approximation of Functions of Many Variables and Embedding Theorems]. Moscow, Nauka, 1977. (in Russian)

6. Kostin V.A., Kostin A.V. K teorii funkcional'nyh prostranstv Stepanova [To the Theory of Stepanov Function Spaces]. Voronezh, VSU Press, 2007. (in Russian)

7. Levitan B.M. Pochti-periodicheskie funkcii [Almost Periodic Functions]. Moscow, Gosudarstvennoe izdatel'stvo tekhniko-teoreticheskoy literatury, 1953. (in Russian)

8. Hille E., Phillips R.S. Functional Analysis and Semi-Groups. Providence, American Mathematical Society, 1957.

Received February 26, 2019

УДК 517.9

DOI: $10.14529 / \mathrm{mmp190313}$

\section{АНИЗОТРОПНАЯ ДИФФУЗИЯ В АНИЗОТРОПНЫХ ПРОСТРАНСТВАХ СТЕПАНОВА}

B. A. Горлов, ВУНЦ ВВС «ВВА имени профессора Н.Е. Жуковского и Ю.А. Гагарина», г. Воронеж, Российская Федерация

В статье рассматривается задача, связанная с обработкой изображений и компьютерным зрением. Многие методы помогают решить такой тип задач. Наиболее полезными и интересными из них являются методы уравнений с частными производными, и особое место в этих исследованиях занимает нелинейная диффузия. Фундаментальная теоретическая основа в текущем контексте является центральной частью данного подхода. Итак, в статье введен новый функциональный класс пространств, получена и доказана лемма об эквивалентности нормировки в анизотропных пространствах Степанова, получена лемма о том, что рассматриваемые пространства являются банаховыми. Получена теорема о разрешимости уравнения анизотропной диффузии в анизотропных пространствах Степанова. Результаты могут быть применены к обработке изображений и компьютерному зрению и могут дать новый взгляд на решение данных задач.

Ключевые слова: дифбузия; пространства Никольского; анизотропные пространства Степанова; анизотропная диффузия; дифференциальные уравнения.

Вестник ЮУрГУ. Серия «Математическое моделирование

и программирование» (Вестник ЮУрГУ ММП). 2019. Т. 12, № 3. С. 153-160 


\section{Литература}

1. Gliklikh, Yu.E. Global and Stochastic Analysis with Applications to Mathematical Physics / Yu.E. Gliklikh. - London: Springer, 2011.

2. Deimling, K. Multivalued Differential Equations / K. Deimling. - Berlin; New York: Walter de Gruyter, 1992.

3. Perona, P. Scale-Space and Edge Detection Using Anisotropic Diffusion / P. Perona, J. Malik // IEEE Transactions on Pattern Analysis and Machine Intelligence. - 1990. - V. 12, № 7. P. 629-639.

4. Бесов, О.В. Интегральные представления функций и теоремы вложения / О.В. Бесов, В.П. Ильин, С.М. Никольский. - М.: Наука, 1975.

5. Никольский, С.М. Приближение функций многих переменных и теоремы вложения / С.М. Никольский. - М.: Наука, 1977.

6. Костин, А.В. К теории функциональных пространств Степанова / А.В. Костин, В.А Костин. - Воронеж: ВГУ, 2007.

7. Левитан, Б.М. Почти-периодические функции / Б.М. Левитан. - М.: Государственное издательство технико-теоретической литературы, 1953.

8. Хилле, Э. Функциональный анализ и полугруппы / Э. Хилле, Р. Филлипс. - М.: Издательство иностранной литературы, 1962.

Владимир Александрович Горлов, кандидат физико-математических наук, доцент, Военный учебно-научный центр ВВС «Военно-воздушная академия имени профессора Н.Е. Жуковского и Ю.А. Гагарина» (г. Воронеж, Российская Федерация), gorlov.v.a@gmail.com.

Поступила в редакиию 26 февраля 2019 г. 